\title{
Non-durational indices in Italian geminate consonants
}

\author{
Elinor M. Payne \\ Department of Phonetics and Linguistics \\ University College London \\ elinor@phon.ucl.ac.uk
}

\begin{abstract}
This paper presents the results of an electropalatographic investigation into non-durational properties of Italian consonant gemination. The evidence suggests a more palatalised tongue configuration during the production of geminate coronal sonorants and stops than in their non-geminate counterparts. Evidence is also found of differences in the active articulator, with a laminal articulation more characteristic of geminates, and an apical articulation of non-geminates. It is proposed that Italian gemination be thought of more broadly as fortition, and the implications of this are discussed.
\end{abstract}

\section{Introduction}

This paper presents the results of an electropalatographic investigation into non-durational indices of Italian consonant gemination. The durational properties of geminates are wellknown and have been the focus of much study, both in Italian (e.g. Marotta 1986, Agostiniani 1992, Ericsdotter 1998, Payne 2005) and other languages (e.g. Ladd \& Scobbie 2003 for Sardinian; Arvaniti 1999, Muller 2001 for Cypriot Greek; Lahiri \& Hankamer 1988 for Turkish and Bengali; Ham 2001 for Hungarian, Levantine Arabic, Madurese and Bernese German; Local \& Simpson 1999 for Malayalam; Louali \& Maddieson 1999 for Berber; Cohn, Ham \& Podesva 1999 for three languages of Indonesia). However, several studies have also investigated non-durational indices, and shown that production may differ also in non-temporal dimensions. For example, Abramson $(1991,1999)$ reports a greater intensity in the burst of geminate stops, and systematic differences in $\mathrm{F}_{0}$ in following vowels for Pattani Malay. Local \& Simpson (1999) report the impression of a clear (more palatalised) resonance for geminate sonorants in Malayalam. This finding was echoed in a study of Italian geminate laterals in Payne (2005), which found that the formant structure of geminate alveolar laterals was clearer than that of their non-geminate counterparts, though not as clear as that of palatal laterals (which are always geminate in Italian).

The aim of the current investigation was to extend this study of Italian geminate laterals by employing a more direct means of articulatory investigation, namely electropalatography (EPG). By revealing patterns of linguo-palatal contact, it was hoped that EPG would shed more light on potential differences in gestural configuration, as suggested by the formant analysis. The present study also extends analysis to other coronals, and considers more closely the possible differences between lexical and post-lexical geminates. 
Table 1 Types of long consonant in Standard Italian.

\begin{tabular}{|c|c|}
\hline 1 & $\begin{array}{l}\text { Word-internal, lexically contrastive, with phonemic status } \\
\text { e.g. pappa [p'ap:a] 'mush' }\end{array}$ \\
\hline 2 & 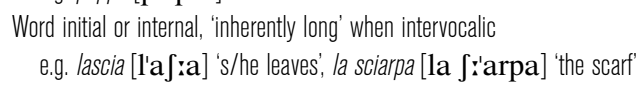 \\
\hline 3 & $\begin{array}{l}\text { Word initial, post-lexical, prosodically triggered RS } \\
\text { e.g. virtù diversa [virt'u d:iv'crsa] 'different virtue' }\end{array}$ \\
\hline 4 & $\begin{array}{l}\text { Word initial, post-lexical, lexically triggered RS } \\
\text { e.g. e Roma [e r:'oma] 'and Rome' }\end{array}$ \\
\hline 5 & $\begin{array}{l}\text { Low-level, non-obligatory, phonetic assimilation of clusters } \\
\text { e.g. tecnico [t'en:iko] 'technical' }\end{array}$ \\
\hline 6 & $\begin{array}{l}\text { Low-level, word boundary false geminates } \\
\text { e.g. al lido [al:'ido] 'to the lido (beach resort)' }\end{array}$ \\
\hline
\end{tabular}

\section{Parameters of investigation}

The parameters of investigation in the present study are almost identical to those employed in the earlier acoustic study. What follows is an abbreviated explanation of these parameters as outlined in Payne (2005). The main differences are that in the present study the target word or words are examined for only one position (nuclear) in the phrase; a full set of 'inherent' geminates is examined; and, in addition to laterals, nasals and alveolar stops are examined.

\subsection{Geminate type}

In present-day Standard Italian, there are arguably six types of long consonant, or geminate (see table 1). As a departure from convention, stress is marked immediately before the vowel, rather than at the beginning of the syllable. This is because geminate consonants are usually considered ambisyllabic, and marking stress before syllable-initial consonants would be problematic. Conventionally, Types 1,2,3 and 4 are classed as phonologically long consonants, or geminates, while Types 5 and 6 are classed as phonetically long consonants. Type 1 is lexically determined and contrasts phonemically with non-geminates (e.g. pappa vs. papa 'mush' vs. 'pope'). Type 2 consists of a set of consonants that are always phonetically long intervocalically and for which no contrasting non-geminate exists. They are conventionally classed also as phonologically long and it is assumed that the absence of a short (nongeminate) variant is the result of a defective paradigm. Types 3 and 4 are the result of a post-lexical process known as RADDOPPIAMENTO SINTATTICO (RS), or 'syntactic doubling'. In Type 4, certain lexical items (e.g. in table 1: $e$ 'and') will trigger gemination of the first consonant of the following word. Type 4 is present also in other central and southern dialects and varieties of Italian, though trigger words vary regionally. Type 3 is present only in certain central dialects and varieties of Italian, including the variety examined here (Standard Italian as spoken in Rome). Unlike Type 1 geminates, which in Standard Italian at least only appear word-internally, Type 2 geminates may also combine with an RS environment (either lexical or prosodic), e.g. e sciarpe 'and scarves'. In other words, Type 2 may interact with Types 3 and 4 . In this case, the geminate remains long, and, as shown by Payne (2005), no extra lengthening occurs.

Out of these six possible types, only three types were investigated: lexical (1); inherent (2); and prosodically triggered RS (3). Lexically determined RS (type 4) was not included because, being restricted to only a few trigger words, conditions could not be controlled. Low-level assimilatory geminates (Types 5 and 6) were not included for similar reasons. 
Table 2 Inherently long consonants. (All examples are phonetically long, except for the post-consonantal context (B).)

\begin{tabular}{|c|c|c|c|}
\hline$A$ & lasciare & 'to leave' & [la $\int$ :'are $^{\prime}$ \\
\hline B & non sciacqua & 's/he doesn't rinse' & [non J'ak:wa] \\
\hline C & la sciacqua & 's/he rinses it & [la f:'ak:wa] \\
\hline D & avrà sciarpe & 's/he will have scarves' & [avr'a f:'arpe] \\
\hline
\end{tabular}

Table 3 Consonant types investigated.

\begin{tabular}{lccc}
\hline & Non-geminate & Geminate & Inherently geminate \\
\hline Position in word & Word-internal/word-boundary & Word-internal/word-boundary & Word-internal only \\
\hline Laterals & 1 & $\mathrm{l}$ & $\mathrm{K}:$ \\
Nasals & $\mathrm{n}$ & $\mathrm{n}:$ & $\mathrm{n}:$ \\
{$[+$ voice] coronal stops/affricates } & $\mathrm{d}$ & $\mathrm{d}:$ & $\mathrm{dz:}$ \\
{$[-$ voice] coronal stops/affricates } & $\mathrm{t}$ & $\mathrm{t}:$ & $\mathrm{ts:}$ \\
{$[-$ voice] coronal fricatives } & $\mathrm{s}$ & $\mathrm{s:}$ & $\int:$ \\
\hline
\end{tabular}

The purpose of investigating different geminate types was to ascertain whether underlying structural differences are reflected in phonetic dissimilarity. Since consonant gemination word-internally (lexical geminates) can be the basis of a semantic contrast, while consonant gemination word-initially arises as a post-lexical process, it was hypothesised that some distinction between the two would be observable in gestural configuration. Specifically, it was hypothesised that word-boundary (post-lexical) geminates might resemble more closely non-geminates, since one possible interpretation of post-lexical gemination is as a surface process that merely lengthens an underlying non-geminate.

\subsection{Inherently long consonants}

The consonants $/ \kappa: \mathrm{j}: \mathrm{d} 3: \mathrm{t} \int: \int: /$ are long when intervocalic (see A and $\mathrm{C}$, table 2 ) and short elsewhere (e.g. B) (see Canepari 1999: 85; Rogers \& d'Arcangeli 2004: 117; Payne 2005). For this study, only word-internal examples were used (A in table 2).

\subsection{Consonant type}

With one small qualification, all consonant phonemes in Italian can be geminate: /p: b: t: d: k:

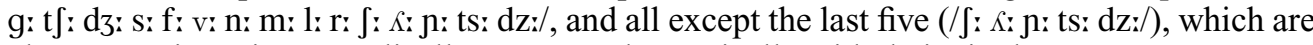
always geminate intervocalically, contrast phonemically with their singleton counterparts. In the present study, five series of consonant types were examined: [ $\mathrm{d} l \mathrm{n} \mathrm{s}$ ] and their geminate counterparts, plus the closest-matching inherent geminates [ $[: \kappa: \mathrm{n}:$ ts: dz:] (see table 3 ). The situation regarding /s s:/ is regionally complex (see Payne 2005 for a brief discussion); however, in the variety investigated here (Standard Italian as spoken in Rome), both forms are voiceless.

The motivation for including a complete set of inherent geminates was an observation in Payne (2005) that /1: lay somewhere on a cline between $/ \mathrm{K}: /$ and $/ 1 /$ in terms of both formant structure (decreasing palatalisation) and duration. One of the aims of the present study was to extend this comparison to other coronals for which a closely matching palatal/palatal-alveolar inherent geminate exists. 
Table 4 Lexical stress conditions tested.

\begin{tabular}{|c|c|c|c|c|c|}
\hline \multicolumn{3}{|c|}{ Word-internal (WI) } & \multicolumn{3}{|c|}{ Word-boundary (WB) } \\
\hline & Non-geminate & Geminate & & Geminate & Non-geminate \\
\hline Pre-stress & $V C^{\prime} V$ & $V C: ! V$ & Pre-stress & 'V\#C:'V & V\#C'V \\
\hline Post-stress & 'VCV & VC:V & Pre-unstressed & 'V\#C:V(C'V) & V\#CV(C'V) \\
\hline Unstressed & VCV & VC:V & Minimally stressed & 'V\#C:V(CV) & V\#CV(CV) \\
\hline
\end{tabular}

\subsection{Prosodic factors}

Lexical stress conditions tested are set out in table 3. Consonants were in one of three positions: i) immediately before the main stress of the word (PRE-STRESS); ii) either immediately after the main stress of the word (POST-STRESS), if word-internal, or before an unstressed syllable (PREUNSTRESSED), if word-boundary; iii) either between two unstressed vowels (UNSTRESSED), if word-internal, or before two unstressed syllables (MINIMALLY STRESSED), if word-boundary. As can be seen from table 4, conditions could not be identical across the different types of geminate since at word boundaries post-stress consonants are necessarily geminate and non-geminates cannot be post-stress, whereas word-internally post-stress consonants can be geminate or non-geminate. The shaded boxes indicate those prosodic conditions that diverge from the 'norm'. For example, in the pre-stress condition, in only three out of four cases, the preceding syllable is unstressed: for word-boundary geminates, the preceding syllable is also, inevitably, stressed. Consonants were tested in the NUCLEAR position of the intonational phrase. e.g. il vento CALA 'the wind drops'.

\section{Method}

\subsection{Speaker}

The speaker was female, in her mid-thirties and from Rome. Though the Roman accent is quite distinctive, it is phonologically very close (in terms of having an identical phoneme inventory, phonotactic rules and having consonant gemination) to the (somewhat idealised) Standard Italian. Most importantly, it has prosodically triggered RS, therefore allowing a comparison with the acoustic data investigated in Payne (2005), taken from speakers of Pisan Standard Italian.

\subsection{Presentation of material}

The test material consisted of a series of words, containing those conditions of interest, embedded in carrier sentences. Each consonant appeared in or across actual words (depending on whether the target consonants were word-internal or word-boundary). These words are listed in the appendix. The immediate vowel context was always $/ \mathrm{aCa} /$. As with the acoustic study, because of the different types of geminate tested and the different conditions in which they appear (e.g. word-internal versus word-boundary), it was not possible to have a consistent sentence frame. However, efforts were made to keep to sentence duration roughly equal (i.e. number of syllables), and sentence type consistent (so as not to induce big differences in intonational phrasing, which could have affected segment duration). 


\subsection{Procedure}

The system used was EPG3, developed by Reading University. The electropalate in this system contains eight rows of electrodes spaced between the point where the top teeth meet the gum and the back of the hard palate. The first row has six electrodes, and the other seven rows have eight electrodes each, making a total of 62 electrodes. Contact is recorded at a sampling rate of 100 frames per second, along with a low bandwidth acoustic reading, both of which are then analysed on a PC.

The subject was given time to become accustomed to speaking with the electropalate in place. Only when the author felt her speech was sufficiently natural and fluent did recording begin. Having familiarised herself with the carrier sentences in which the consonants of interest were embedded, the subject read these five times (each in randomised order) at her normal speaking rate, repeating any utterances she or the author deemed not to have been delivered naturally. The recording took place in a soundproof room at the Cambridge University Phonetics Laboratory.

\subsection{Analysis}

An electropalate is shaped to fit a particular subject whose vocal tract anatomy is unique, and data interpretation must take this into account. In the present experiment, the front-most row (R1) corresponds to where the subject's top front teeth join the gum. The subject did not have an alveolar RIDGE as such, and so the whole of the pre-palatal area, corresponding to R2-4 (rows 2-4), consists of a slope up from the base of the teeth to the beginning of the hard palate. R5-8 correspond to the hard palate itself, with R8 lying along the back edge of the hard palate, close to the soft palate. A brief impressionistic analysis showed that the constriction area for non-palatal consonants coincided with R1-4, i.e. the subject's alveolar 'slope'.

The percentage of activated electrodes in the 'constriction area' was calculated for each consonant tested, for the frame during which maximum contact occurred. For affricates this was always during the stop portion of the consonant. In addition, the location (rows) and shape of constriction were observed.

\section{Results}

\subsection{Amount of contact}

The constriction during the 'alveolar' consonants was formed in the alveolar area, ruling out the possibility of an actual palatal constriction. However, a general raising of the tongue body is likely to result in a greater amount of contact around the actual constriction, and therefore a higher percentage of activated electrodes in the constriction area (R1-4) was interpreted as possibly indicating a more palatalised vocal tract configuration.

Geminate nasals, laterals and stops almost always involved more linguopalatal contact than their non-geminate counterparts, regardless of stress and position in the word (figure 1 shows a graph of results for nasals). The difference is around $10-35 \%$ for nasals and laterals and $20-70 \%$ for alveolar stops, with the greatest differences in word-boundary pre-stress ' $t$ ' and word-internal pre-stress ' $\mathrm{d}$ ' (mainly because of lenition: the non-geminate is realised as a fricative). One striking exception is word-boundary pre-unstressed ' $t$ ', when the amount of contact is much reduced in the geminate and increased in the non-geminate. This is curious since the geminate/non-geminate contrast is particularly large for other consonants in this condition.

As expected, palatal nasals and laterals were articulated with greater linguopalatal contact than their alveolar equivalents. Consequently, there is a gradient of increasingly palatalised 


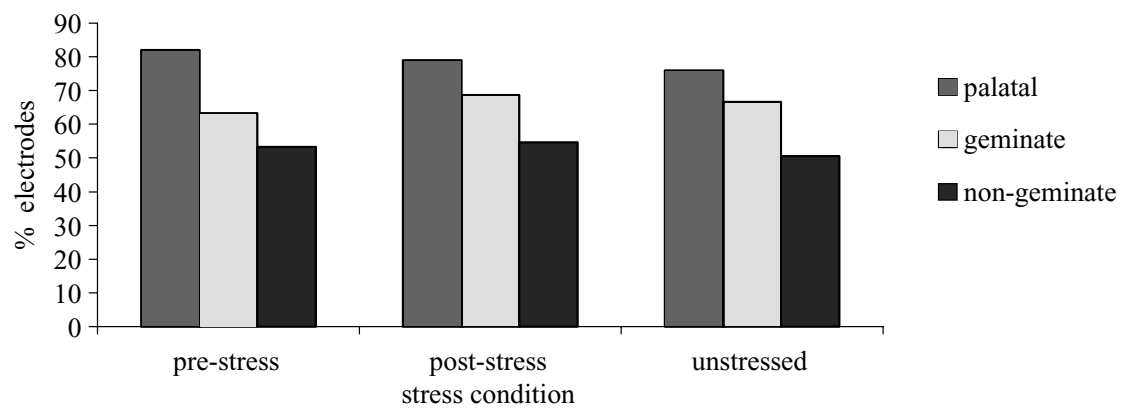

Figure $1 \%$ constriction area activated in palatal, geminate and non-geminate nasals as a function of stress.

tongue configuration from $/ \mathrm{n} 1 />/ \mathrm{n}: 1: />/ \mathrm{n}: K: /$, supporting observations of gradiency in the formant structure of laterals, as observed in Payne (2005). Likewise, the voiced affricate, which is also inherently geminate, displayed more linguopalatal contact than its geminate stop equivalent, except when pre-stress. However, the voiceless affricate displayed LESS linguopalatal contact than its (geminate) stop equivalent.

\subsection{Active and passive articulators}

Differences in the amount of contact between geminates and non-geminates may simply be the result of differing temporal windows available for an articulation to occur. Evidence of differences in articulator, passive and/or active, would provide clearer indication of possible differences in gestural plans. Locating the passive articulator with EPG is relatively straightforward: the activated electrodes indicate where the constriction was made; even if closure is not made, it is relatively simple to deduce the constriction area from those electrodes that ARE activated. Information about the active articulator is not so easily extrapolated. Pandeli (1993: 18-34) infers the active articulator from contact patterns anterior to the main constriction, and a comparison with pre-existing palatograms for which matching linguograms and/or X-rays also exist. However, the patterns that emerge from her data are of limited use here since, for many tokens, contact extends to, and possibly beyond, R1, and anterior contact patterns cannot be known. Articulatory introspection can help build a picture of individual gesture dynamics. Since different zones of the tongue have varying degrees of autonomy (the tongue tip is relatively independent, the tongue blade and dorsum much less so) these can be roughly correlated with particular depths of constriction. For example, a constriction several rows deep is unlikely to be exclusively apical, while a single row/column of contact around the front/sides of the electropalate would indicate an apical articulation, with a concave tongue body configuration.

Figure 2 shows averaged representations of EPG readings for NASALS and LATERALS. Black squares represent electrodes activated during peak contact in at least $4 / 5$ tokens. Grey squares represent the same in $3 / 5$ tokens. The plate is viewed from above, with the row closest to the teeth (R1) at the top.

In PALATALS, there is a COMPLETE OCCLUSION 3-4 rows deep, with the constriction extending behind R4, indicating that the tongue BLADE and/or DORSUM is the active articulator. The lateral contact in the nasal is at least 2 columns deep, indicating that the TONGUE IS HELD HIGH IN THE MOUTH, resulting in a palatalised vocal tract configuration, as would be expected.

The GEMINATE involves a COMPLETE OCCLUSION for all conditions. The constriction is 'flat-edged' and 2-3 ROWS deep, suggesting the use of the BLADE or TIP AND BLADE. At 


\begin{tabular}{|c|c|c|c|c|c|}
\hline & \multicolumn{3}{|c|}{ Word internal } & \multicolumn{2}{|c|}{ Word boundary } \\
\hline $\mathrm{N}$ & Palatal & Geminate & Non-geminate & Geminate & Non-geminate \\
\hline Pre-stress & & & & & \\
\hline $\begin{array}{l}\text { Post-stress/pre- } \\
\text { unstressed }\end{array}$ & 曲曲 & 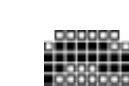 & & & \\
\hline $\begin{array}{l}\text { Unstressed/minimally } \\
\text { stressed }\end{array}$ & & & & & \\
\hline
\end{tabular}

\begin{tabular}{|c|c|c|c|c|c|}
\hline & \multicolumn{3}{|c|}{ Word internal } & \multicolumn{2}{|c|}{ Word boundary } \\
\hline $\mathrm{L}$ & Palatal & Geminate & Non-geminate & Geminate & Non-geminate \\
\hline Pre-stress & 曲曲 & 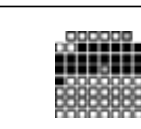 & 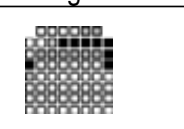 & 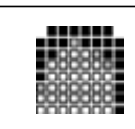 & 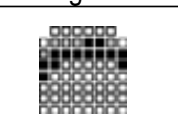 \\
\hline $\begin{array}{l}\text { Post-stress/pre- } \\
\text { unstress }\end{array}$ & & 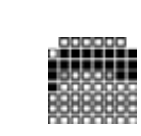 & 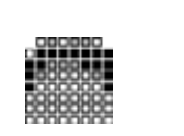 & 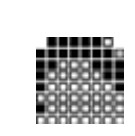 & 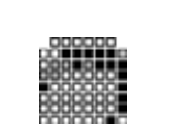 \\
\hline $\begin{array}{l}\text { Unstressed/minimally } \\
\text { stressed }\end{array}$ & 曲曲 & 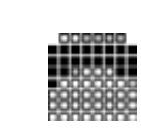 & 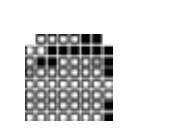 & 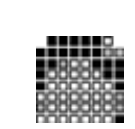 & 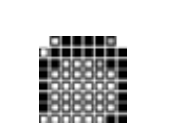 \\
\hline
\end{tabular}

Figure 2 Averaged EPG readings for nasals and laterals.

word boundaries, the constriction is slightly further forward for both the lateral and nasal, and, in the lateral alone, also less deep and less 'flat-edged'. Also in the lateral, there is an unobstructed lateral opening behind the main constriction. The deep, laminal constriction in geminate nasals - squarely along the alveolar area and with no posterior contact except for at the sides - suggests a FLATTISH tongue configuration. A similar configuration is deducible from the traces observed for the word-internal geminate lateral, without the posterior contact at the sides. However, in the word-boundary geminate lateral, the fact that the constriction is further forward and less flat-edged, and that there is more contact down the sides of the palate, suggests a possibly more CUPPED configuration.

In the NON-GEMINATE, the constriction is 1 or $1-2$ rows deep (providing it does not reach in front of R1) and, in the nasal, further forward. A complete occlusion only occurs word-internally or, if word-boundary, only when pre-stress in nasals, and in laterals only post-stress when word-internal, and pre-stress or minimally stressed at word boundaries. The evidence suggests an APICAL articulation in both cases, with a FLATTISH, or possibly SLIGHTLY CUPPED tongue. The nasal is often less flat-edged on its inner edge (edge closest to the back of the mouth). In the lateral, there is greater tendency for lateral contact behind the main 


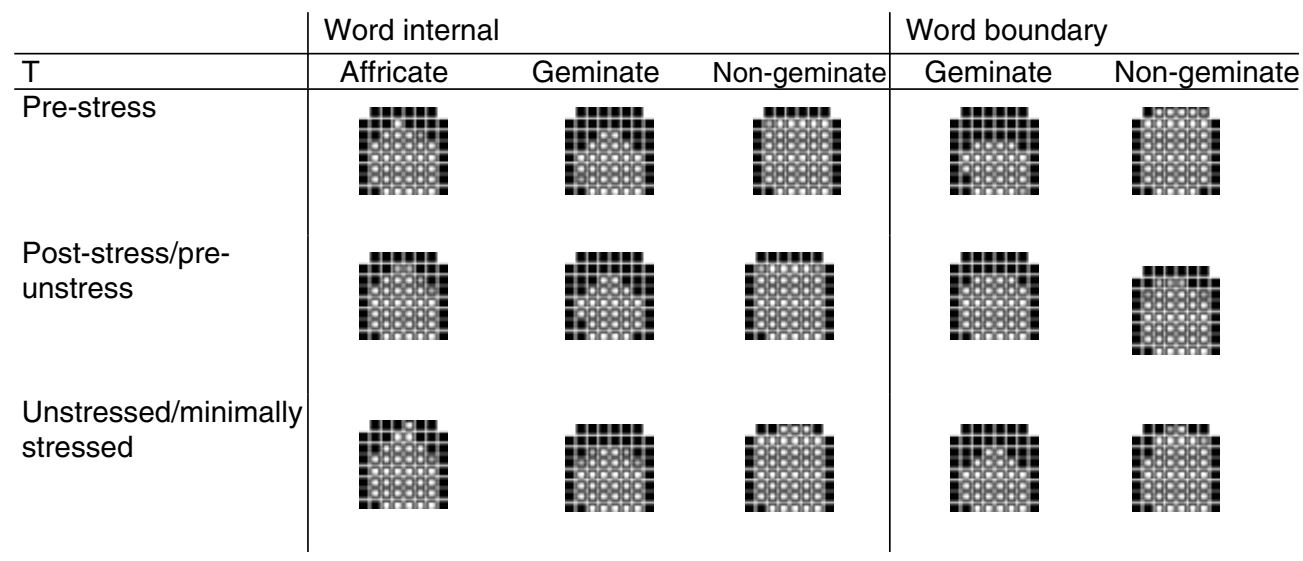

\begin{tabular}{|c|c|c|c|c|c|}
\hline $\mathrm{D}$ & Affricate & Geminate & Non-geminate & Geminate & Non-geminate \\
\hline Pre-stress & & 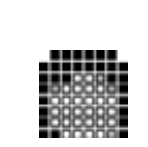 & 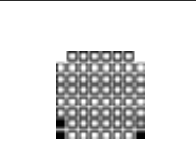 & 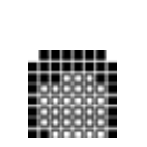 & 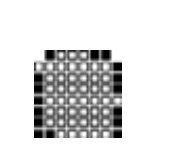 \\
\hline $\begin{array}{l}\text { Post-stress/pre- } \\
\text { unstressed }\end{array}$ & 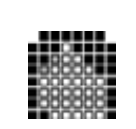 & 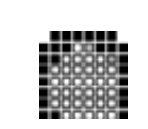 & 186889 & 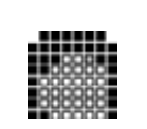 & 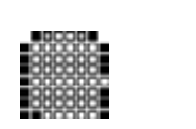 \\
\hline $\begin{array}{l}\text { Unstressed/minimally } \\
\text { stressed }\end{array}$ & 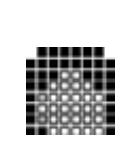 & 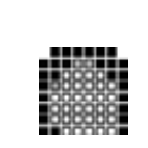 & 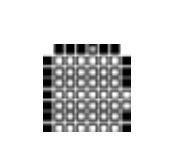 & & \\
\hline
\end{tabular}

Figure 3 Averaged EPG readings for stops and affricates.

constriction, particularly at word boundaries and when minimally stressed when the lateral contact is virtually complete on both sides. Unless a lateral opening lies behind the palate, out of view, the consonant produced is not, strictly speaking, a lateral.

Figure 3 shows averaged representations of EPG readings for STOPS and AFFRICATES. Again, black squares represent electrodes activated during peak contact in at least $4 / 5$ tokens. Grey squares represent the same in $3 / 5$ tokens. The plate is viewed from above, with the row closest to the teeth (R1) at the top.

AFFRICATES are completely occluded (during the stop portion), except when wordinternal and unstressed (voiceless series). Contact pattern is very similar to geminates, though less flat-edged and, in the voiceless series, also slightly less deep.

GEMINATES are COMPLETELY OCCLUDED, 2 (voiced) or 2-3 (voiceless) rows deep. The constriction shape is more flat-edged and slightly deeper at word boundaries than for wordinternal geminates. The contact suggests an APICO-LAMINAL articulation for word-internal geminates, and a laminal or APICO-LAMINAL articulation for word-boundary geminates. In both cases, the evidence suggests a fairly FLATTISH or slightly CUPPED tongue configuration. There is complete but narrow side contact behind the main constriction in all cases. 


\begin{tabular}{|c|c|c|c|c|c|}
\hline Fricative & Palatal & Geminate & Non-geminate & Geminate & Non-geminate \\
\hline Pre-stress & 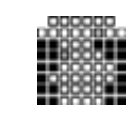 & & & 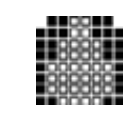 & $\begin{array}{l}H 889 \\
88898\end{array}$ \\
\hline $\begin{array}{l}\text { Post-stress/pre- } \\
\text { unstressed }\end{array}$ & 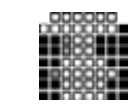 & 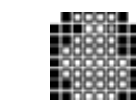 & 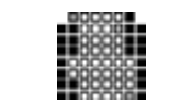 & 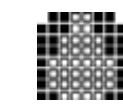 & 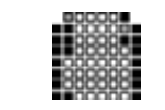 \\
\hline $\begin{array}{l}\text { Unstressed/minimally } \\
\text { stressed }\end{array}$ & 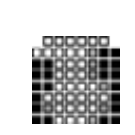 & & & & 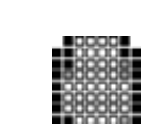 \\
\hline
\end{tabular}

Figure 4 Averaged EPG readings for fricatives.

NON-GEMINATES tend to be non-occluded. Complete occlusion only occurs post-stress or, if word-internal, pre-stress, in the voiceless series, and not at all in the voiced series (though occlusion is almost complete in word-internal post-stress and non-stress conditions, and in word-boundary minimally stressed conditions). In other words, there is a strong tendency to articulate intervocalic stops, especially voiced ones, as a fricative or approximant. Where occlusion is complete, the constriction is only 1 row deep (as far as can be observed). Furthermore, there is a complete but narrow lateral contact in all cases, strongly suggesting an APICAL articulation, with a fairly CUPPED tongue configuration. The one exception is the pre-stress word-internal voiced stop, for which only minimal contact is made on the back rows of the palate, making it impossible to deduce anything about tongue shape. In this condition, the stop is fully lenited. Full LENITION occurs only word-internally, and this may be because word-initial consonants play a greater role in lexical accessing and are, therefore, less prone to lenition.

Figure 4 shows averaged representations of EPG readings for fricatives. As would be expected, the main constriction in the palatal-alveolar is formed further back (R3-4) than in the alveolar. However, the hypothesis that the main constriction in the geminate alveolar would be slightly further back (and therefore more palatal) than in the non-geminate is not borne out. If anything, the constriction reaches slightly further forward. The main observable difference between geminate and non-geminate is a DIFFERENCE IN LATITUDINAL DEPTH: the constricted area is 'thicker' (i.e. more columns activated) in the geminate. In the GEMINATE, the unconstricted air passage narrows down to 2-3 columns, while in the NON-GEMINATE it narrows down only to 3-4 columns, with the contrast more obvious at word boundaries. Assuming air pressure is constant, this difference in the volume of the air passageway will affect the velocity and, therefore, the frequency of the noise generated. It is, therefore, possible that the sound generated by the geminate reaches discernibly higher frequencies than that produced by the non-geminate, with possible perceptual relevance.

\section{Discussion}

The EPG investigation points to a more palatalised vocal tract configuration in geminate laterals, coronal stops and nasals, with geminates involving greater linguo-palatal contact than their non-geminate counterparts. This 'palatal effect' does not mean that articulations 
are made in the palatal area, but that the tongue is higher and flatter in the mouth, giving the overall tongue configuration a more palatalised quality. This reinforces the acoustic findings in Payne (2005), which showed that geminate laterals had a more clear formant structure than non-geminates. The EPG records also indicate that a different part of the tongue, and different overall shape of the tongue, may be involved in the articulation of coronal geminate sonorants and stops. The evidence suggests that geminates are produced more with the tongue blade or blade and tip, while non-geminates are more straightforwardly apical. There is also some evidence that, while the tongue is flattish during the geminate articulation (particularly in lexical geminates), it may be slightly cupped (concave) during non-geminates, particularly in stops. The various parameters of difference observed are mutually compatible, since a flatter, more laminal constriction would correspond both with a greater degree of linguo-palatal contact and a more palatalised vocal tract configuration.

These findings add weight to the suggestion, advanced by Payne (2005), that the distinction of phonological length in Italian may not be phonetically interpreted through durational differences alone. As Payne (2005) discusses, the theoretical implications of this are less than clear. From a gestural point of view, the more palatalised configuration of the vocal tract during geminates may be interpreted as the unintended result of extended duration. During the shorter non-geminate there is less time for the articulators to reach their target, and, as a consequence, gestural undershoot occurs, resulting in less linguo-palatal contact. This is the analysis proposed for domain-initial consonant strengthening in Korean by Cho \& Keating (2001), who find a strong correlation between linguo-palatal contact and duration and conclude that 'strengthening' and 'lengthening' are a single effect in Korean. This is a mechanical interpretation, with differences occurring in the phonetic implementation of the same underlying gestural target. The only difference between the phonological representation for geminates and non-geminates lies in their temporal aspect, which can be expressed orthogonally to spatial attributes, for example, by adding the feature [+long] or, in Articulatory Phonology (see e.g. Browman \& Goldstein 1992), adjusting gestural stiffness.

This would be a possible interpretation of what we observe for the articulation of the geminate and non-geminate coronal fricative, the difference appearing to be in degree of gestural target attainment, rather than a difference in active or passive articulator. There may, however, be simply less room for manoeuvre in the precision articulation of a fricative, preventing a different gestural configuration: a more palatalised configuration could easily topple over into the palatal-alveolar $/ \mathrm{J} /$. However, differences in the shape of the tongue for the coronal stops, laterals and nasals are more difficult to explain as the mechanical fall-out of temporal differences. Also, if articulatory 'fortition' (i.e. greater contact) were merely a result of longer duration, we would expect the palatal effect to be uniform, or at least consistent with variation in duration, and this is not the case with Italian (Payne 2005). We might also reasonably expect cross-linguistic similarities, but again, there is counter-evidence: Eftychiou (2004) reports a DARKER resonance for geminate laterals in Cypriot Greek, and this is supported by observations made in her EPG analysis.

The alternative analysis is that the observed differences in linguo-palatal contact, and in formant structure (Payne 2005), are the result of an underlying structural difference that is not merely temporal. In other words, the underlying gestures for $/ 1: \mathrm{t}: \mathrm{n}: /$ would be SPATIALLY different from the gestures for $/ 1 \mathrm{t} \mathrm{n} /$. If this were the case, we might reasonably expect geminates resulting from the post-lexical process of RS to resemble non-geminates more closely than lexical geminates, since underlyingly they originate from non-geminates. In the formant analysis in Payne (2005), it was indeed found that palatal effects were stronger wordinternally than at word boundaries, particularly with respect to $\mathrm{F} 1$, and the tentative conclusion from this was that non-durational indices of gemination are a more robust feature of LEXICAL geminates, and that only this type of geminate is gesturally different from non-geminates. In the present study, the observed differences in gestural configuration are difficult or impossible to quantify, and therefore it is difficult to gauge how far they lend support to conclusions drawn 
from the formant analysis. In addition, only in the case of the lateral is there any indication of a possible distinction between word-internal and word-boundary geminates, with the latter, arguably, resembling the patterns of non-geminates more than those of lexical geminates. As with the gestural account, if we conceive of the palatal effect to be a structural add-on to ALL true (lexical) geminates, then we might reasonably expect to see a clear distinction between lexical (word-internal) and post-lexical (word-boundary) geminates in nasals and stops too. We do not. Also, as Payne (2005) has shown, there appear to be fortitional effects resulting from position in relation to stress, with non-geminates displaying a clearer formant structure when post-stress than in other positions.

As the author implied in the earlier paper, fortitional effects may be thought of as operating at both phonological and phonetic levels. This would be precisely in accordance with the way that lengthening, in the same study, was shown to occur both phonetically and phonologically (i.e. as a result of RS, a phonological process of lengthening, and as a result of post-stress position, at the phonetic level). In other words, fortition, in terms of both duration and palatal effects, may be directly expressed in lexical geminates, and therefore PHONOLOGICALLY ENCODED from the outset, but merely ACQUIRED, either phonetically or phonologically, in post-lexical geminates. How fortition is interpreted phonetically may be determined by a combination of universal gestural considerations and language-specific 'choices'. Other things being equal, longer duration is more likely to result in a greater amount of contact, and therefore universal tendencies may emerge. At the same time, specific languages may employ particularised articulatory strategies in interpreting the phonological distinction, as a comparison with Cypriot Greek geminate laterals would suggest.

\section{Conclusion}

This study has presented further evidence that, in addition to well-known durational differences, geminate consonants appear to be SPATIALLY distinct from non-geminates. This would suggest that, at least in Italian, gemination is to be considered more generally as a FORTITIONAL process. If STRENGTHENING were shown to be an inevitable result of LENGTHENING, this would mean that the primary underlying distinction is one of phonological length, and that fortition is part of the phonetic interpretation of this distinction. However, the data would indicate that this is not the case. While differences in the amount of contact may depend on temporal differences, observed differences in the place of constriction and inferred differences in the active articulator are less easy to explain mechanistically. It may therefore be more appropriate to consider the underlying distinction as fortitional, while at the same time acknowledging that phonetic processes of fortition, governed, for example, by prosodic factors, may also be operative in any given language. More broadly, the difficulty in distinguishing phonological from phonetic triggers of fortition reflects perhaps a more fundamental difficulty in drawing boundaries between phonology and phonetics, a difficulty only compounded by cross-linguistic differences.

\section{Acknowledgements}

The author wishes to thank the British Academy for the funding of a Postdoctoral Fellowship in the Department of Linguistics, University of Cambridge, Geoff Potter for technical assistance, Francis Nolan, Edda Farnetani, the late Peter Ladefoged, John Esling and an anonymous JIPA referee for their helpful comments on an earlier version of this paper. 


\section{Appendix: Target words used}

Table A1 Word-internal.

\begin{tabular}{|c|c|c|c|c|c|c|}
\hline & \multicolumn{3}{|c|}{ Geminate } & \multicolumn{3}{|c|}{ Non-geminate } \\
\hline & Pre-stress & Post-stress & Unstressed & Pre-stress & Post-stress & Unstressed \\
\hline \multirow[t]{2}{*}{1} & ballare & balla & ballatoio & calare & cala & calamari \\
\hline & 'to dance' & 's/he dances' & 'small balcony' & 'to subside' & 'it subsides' & 'squid' \\
\hline \multirow[t]{2}{*}{$\mathrm{n}$} & dannare & canna & cannabismo & sanare & sana & sanatorio \\
\hline & 'to damn' & 'rod & 'cannabism' & 'to cure' & 'healthy' & 'sanatorium' \\
\hline \multirow[t]{2}{*}{$\mathrm{d}$} & addazia & Gadda & Maddalena & badare & bada & badalucco \\
\hline & 's/he declares' & (proper name) & (proper name) & 'to care' & 's/he cares' & 'fool' \\
\hline \multirow[t]{2}{*}{$\mathrm{t}$} & fattaccio & fatta & battagliere & fatale & fata & fatalismo \\
\hline & 'nasty fact' & 'done (f.sg.)' & 'warrior' & 'fatale' & 'fairy' & 'fatalism' \\
\hline \multirow[t]{2}{*}{$\mathrm{s}$} & casato & casa & casalinga & cassato & cassa & cassaforte \\
\hline & 'married' & 'house' & 'housewife' & 'repealed"' & 'chest' & 'safety box' \\
\hline \multirow[t]{2}{*}{$\overline{\Lambda:}$} & tagliare & taglia & tagliatelle & - & - & - \\
\hline & 'to cut' & 's/he cuts' & 'type of pasta' & - & - & - \\
\hline \multirow[t]{2}{*}{$\mathrm{n}:$} & bagnati & cagna & bagnasciuga & - & - & - \\
\hline & 'wet (pl.)' & 'dog (f.)' & 'shoreline' & - & - & - \\
\hline \multirow[t]{2}{*}{$\mathrm{dz}:$} & azzardo & razza & azzardato & - & - & - \\
\hline & 'Irisk' & 'skate (fish)' & 'risked' & - & - & - \\
\hline \multirow[t]{2}{*}{ ts: } & ammazzare & ammazza & ammazzamento & - & - & - \\
\hline & 'to kill' & 's/he kills' & 'ailling' & - & - & - \\
\hline \multirow[t]{2}{*}{$\int:$} & fasciato & fascia & fasciatura & - & - & - \\
\hline & 'bandaged' & 'strip' & 'bandaging' & - & - & - \\
\hline
\end{tabular}

Table A2 Word-boundary.

\begin{tabular}{|c|c|c|c|c|c|c|}
\hline & \multicolumn{3}{|c|}{ Geminate } & \multicolumn{3}{|c|}{ Non-geminate } \\
\hline & Pre-stress & Post-stress & Unstressed & Pre-stress & Post-stress & Unstressed \\
\hline \multirow[t]{2}{*}{1} & berrà latte & diventarà lattaio & diventerà latitante & beva latte & diventa lattaio & diventa latitante \\
\hline & $\begin{array}{l}\text { 's/he will drink } \\
\text { milk' }\end{array}$ & $\begin{array}{l}\text { 'he'll become a } \\
\text { dairyman' }\end{array}$ & $\begin{array}{l}\text { 's/he'll become a } \\
\text { fugitve' }\end{array}$ & $\begin{array}{l}\text { '(that) you drink } \\
\text { milk' }\end{array}$ & $\begin{array}{l}\text { 'he becomes a } \\
\text { dairyman' }\end{array}$ & $\begin{array}{l}\text { 's/he becomes a } \\
\text { fugitive' }\end{array}$ \\
\hline \multirow[t]{2}{*}{$\mathrm{n}$} & vedrà Napoli & città nascosta & qualità naturale & veda Napoli & ditta nascosta & ragazza naturale \\
\hline & 's/he'll see Naples' & 'hidden city' & 'natural quality' & '(that) you see Naples' & 'hidden firm' & 'natural girl' \\
\hline \multirow[t]{2}{*}{ d } & citerà Dante & città danese & città danneggiata & cita Dante & ditta danese & ditta danneggiata \\
\hline & 's/he'll quote Dante' & 'Danish city' & 'damaged city' & 's/he quotes Dante' & 'Danish firm' & 'damaged firm' \\
\hline \multirow[t]{2}{*}{$\mathrm{t}$} & mangerà tanto & città tabù & città tailandese & mangia tanto & tema tabù & ditta tailandese \\
\hline & 's/he'll eat tuna' & 'taboo city' & 'Thai city' & 's/he eats so much' & 'taboo theme' & 'Thai firm' \\
\hline \multirow[t]{2}{*}{$\mathrm{S}$} & mangerà sale & mangerà salami & mangerà salamini & mangia sale & mangia salami & mangia salamini \\
\hline & 's/he'll eat salt' & 's/he'll eat salamis' & 's/he'll eat little salamis' & 's/he eats salt' & 's/he eats salamis' & 's/he eats little salamis' \\
\hline
\end{tabular}




\section{References}

Abramson, A. S. (1991). Amplitude as a cue to word-initial consonant length: Pattani Malay. In Proceedings of the 12th ICPhS, Aix-en-Provence, August 1991, 98-101.

ABRAMSON, A. S. (1999). Fundamental Frequency as a cue to word-initial consonant length: Pattani Malay. In Proceedings of the 14th ICPhS, Berkeley, August 1999, 591-594.

Agostiniani, L. (1992). Su alcuni aspetti del 'rafforzamento sintattico' in Toscana e sulla loro importanza per la qualificazione del fenomeno in generale. In Quaderni del Dipartimento di Linguistica dell' Università degli Studi, University of Florence 3, 1-28.

ARVANITI, A. (1999). Effects of speaking rate on the timing of single and geminate sonorants. In Proceedings of the 14th ICPhS, Berkeley, August 1999, 595-598.

Browman, C. \& GoldsteIn, L. (1992). Articulatory Phonology: an overview. Phonetica 49, 155-180.

CANEPARI, L. (1999). Manuale di pronuncia italiana (MaPI). Bologna: Zanichelli.

Cho, T. \& KeAting, T. A. (2001) Articulatory and acoustic studies on domain-initial strengthening in Korean. Journal of Phonetics 29, 155-190.

CoHn, A. C., HAM, W. H. \& Podesva, R. J. (1999). The phonetic realisation of singleton-geminate contrasts in three languages of Indonesia. In Proceedings of the 14th ICPhS, Berkeley, August 1999, $587-590$.

EFTYCHIOU, E. (2004). A phonetic investigation of Cypriot Greek consonants in connected speech. M.Phil. dissertation, University of Cambridge.

ERICSDOTTER, C. (1998). Effects of stress and speaking rate on the Italian geminate contrast: durational measurements. Presented at the conference Fonetik 98, Stockholm.

Ham, W. H. (2001). Phonetic and Phonological Aspects of Geminate Timing. New York \& London: Routledge.

LADD, D. R. \& ScobBIE, J. M. (2003). External sandhi as gestural overlap? Counter-evidence from Sardinian. In Local J., Ogden R. \& Temple R. (eds.), Papers in Laboratory Phonology VI: Phonetic Interpretation, 164-182. Cambridge: Cambridge University Press.

LAHIRI, A. \& HANKAMER, J. (1988). The timing of geminate consonants. Journal of Phonetics 16, 327-228.

LOCAL, J. \& SiMPSON, A. (1999). Phonetic implementation of geminates in Malayalam nouns. In Proceedings of the 14th ICPhS, Berkeley, August 1999, 599-612.

LOUALI, N. \& MADDIESON, I. (1999). Phonological contrast and phonetic realisation: the case of Berber stops. In Proceedings of the 14th ICPhS, Berkeley, August 1999, 603-606.

MARotTA, G. (1986). Rhythmical constraints on 'Syntactic Doubling'. Journal of Italian Linguistics 8, $35-52$.

MULLER, J. (2001). The phonology and phonetics of word-initial geminates. Ph.D. dissertation, Ohio State University.

PANDELI, H. (1993). The articulation of lingual consonants: an EPG study. Ph.D. dissertation, University of Cambridge.

PAYNE, E. M. (2005). Phonetic variation in consonant gemination. Journal of the International Phonetic Association 35, 153-189.

Rogers, D. \& D’ARCANgeli, L. (2004). Italian. Journal of the International Phonetic Association 34, 117-121. 